\title{
O Italiano Jurídico no Brasil: uma \\ Pesquisa
}

\author{
Maria Cecilia Casini ${ }^{*}$ \\ Quézea Regina Albolea Mastelaro
}

RESUMO: O presente artigo é um recorte de uma pesquisa realizada acerca do ensino do italiano jurídico no Brasil, que partiu de uma análise dos manuais didáticos de italiano para juristas e das propostas de cursos realizadas com alunos lusófonos que atuam na área jurídica. Iniciamos discorrendo brevemente sobre o surgimento, na Itália, do uso do "vulgar" em documentos jurídicos e do desenvolvimento da língua através do tempo, até assinalar a importância da língua italiana para quem estuda Direito no Brasil. A partir da análise dos livros didáticos especializados, realizamos um curso para o perfil de alunos indicado nesses manuais (nível intermediário), com o intuito de investigar na prática facilidades e dificuldades dos estudantes ao usá-los. Partindo dos resultados desse primeiro curso, projetamos um novo curso para iniciantes absolutos no idioma, trabalhando as quatro habilidades (ouvir, entender, ler e escrever) de forma integrada, com base nos estudos de Balboni (2010), em que os alunos estudaram tanto a língua comum como a língua de especialidade. Para a realização desta pesquisa, partimos dos trabalhos pioneiros realizados por Candido et al. (1977), e naqueles de Celani et al. (2009) e Mordente e Ferroni (2011a; 2011b), e trouxemos nossas observações que esperamos possam contribuir para a expansão da pesquisa na área do italiano com fins específicos.

PALAVRAS-CHAVE: italiano jurídico; fins específicos; ensino do italiano

ABSTRACT: Il presente articolo fa parte di una ricerca sull'insegnamento dell'italiano giuridico in Brasile, realizzata a partire dall'analisi di libri di testo di italiano per giuristi, e presenta proposte di corsi specifici per studenti di lingua portoghese che operano in campo giuridico. Si inizia parlando brevemente dell'uso

*Universidade de São Paulo, São Paulo, SP (Brasil) - casini@usp.br / quezea@gmail.com 
del "volgare" in Italia in documenti giuridici e dello sviluppo di questo tipo di linguaggio nel tempo; ciò per sottolineare l'importanza della lingua italiana per chi studia giurisprudenza in Brasile. A partire dall'analisi di libri di testo esistenti, è stato elaborato un corso adeguato al profilo degli studenti indicati in questi manuali (livello intermedio), al fine di identificare nella pratica le strutture e di dare spazio alle loro difficoltà. Sulla base dei risultati di questo primo corso, è stato progettato un nuovo corso per principianti assoluti nello studio della lingua italiana, in cui veniva affrontata sia la lingua comune sia la lingua specialistica, lavorando in modo integrato a partire dalle quattro abilità linguistiche (ascoltare, capire, leggere e scrivere), basandoci sugli studi di Balboni (2010). Per la ricerca ci siamo basati sul lavoro pionieristico svolto da Candido et al. (1977), e su quelli di Celani et al. (2009) e Mordente e Ferroni (2011a; 2011b). Verranno presentate le nostre osservazioni che speriamo possano contribuire alla diffusione della ricerca sull'italiano per fini specifici.

PAROLE CHIAVE: italiano giuridico; fini specifici; insegnamento dell'italiano

ABSTRACT: This article is a part of the survey on the teaching of Italian language in Brazil, based on the analysis performed with textbooks of Italian for jurists, and on proposals for courses carried out with Portuguese-speaking students, who work in the area of the Law. We started discussing briefly the emergence, in Italy, of the use of "vulgar" in legal documents and the development of the language through time, until the importance of the Italian language for those who study Law in Brazil. From the analysis made of the existing textbooks, we taught a course to students indicated in those books (intermediate level) to investigate advantages and difficulties faced by the students. Based on the results of this first course, we designed a new course for absolute beginners in Italian language, working in an integrated way the four skills (listening, understanding, reading and writing), according to the studies by Balboni (2010), in which the students studied both the common language and the specific language of Law. We based the research on the pioneering work done by Candido et al. (1977), as well as the ones by Celani et al. (2009) and Mordente e Ferroni (2011a; 2011b); and we brought our observations, hoping to expand the research in the field of Italian with specific purposes.

KEYWORDS: juridical Italian; specific purposes; teaching of Italian language 


\section{Introdução}

As línguas não são estáticas, mas organismo vivos que se modificam com o passar do tempo. Podemos dizer que a língua nasce, cresce e, ao final, desaparece. Não é diferente com a língua italiana. Além dos dialetos e da língua literária, existem outras, tantas línguas italianas, para cujo surgimento contribuíram a história, as experiências, as condições socioculturais, econômicas, jurídicas e científicas.

Em muitos casos, não se trata somente de variações geográficas ou de variedades sociais ou de registro, mas de variedades funcionais para uma comunicação que se desenvolve acerca de temas específicos, em âmbitos particulares de setores de atividades e profissões. É nesse contexto que se insere o italiano jurídico.

Além disso, no contexto de internacionalização da universidade, é sabido que os estudantes procuram se aprofundar e se aperfeiçoar nos estudos de áreas específicas e, para isso, procuram o que há de melhor na produção acadêmica de sua área de atuação. Nos diferentes campos do saber, encontramos muitos textos escritos em inglês, porém, na área jurídica existe uma extensa literatura com relevância internacional historicamente conhecida no direito italiano, assim como no direito francês ou no alemão. A influência das doutrinas italianas no direito no Brasil 
é incontestável e um jurista que pretende se aprofundar no estudo dessas teorias vai se deparar com muito material escrito em italiano, eventualmente irá fazer um curso na Itália, ou participará de atividades científicas, e para esses acontecimentos será útil o domínio do idioma italiano.

Não podemos olvidar que ser aprovado em uma prova de proficiência de língua estrangeira é um dos requisitos para o ingresso no Mestrado e no Doutorado, e o italiano é um dos idiomas requeridos. Do mesmo modo, para muitos alunos da graduação ou da pós-graduação, é de suma importância fazer um intercâmbio no país considerado como um dos berços do direito brasileiro.

Neste artigo, fazemos um recorte de uma pesquisa realizada (MASTELARO, 2014) e, por este motivo, apresentaremos brevemente o surgimento do italiano jurídico e discorreremos a respeito da investigação feita sobre o seu ensino no Brasil, realizada por meio de análise de materiais e dos cursos que ministramos.

O objetivo da nossa pesquisa foi, em primeiro lugar, investigar como é tratado o ensino do italiano jurídico no Brasil. Essa investigação foi feita por meio de análise dos livros existentes para o ensino do italiano jurídico e, posteriormente, por meio de cursos realizados para um público que atua nesta área (advogados, estudantes de direito etc.). O objetivo dos cursos foi identificar se os estudantes de Direito poderiam aprender a língua italiana comum concomitantemente ao italiano de especialidade; e se era possível trabalhar as quatro habilidades (compreensão oral, compreensão escrita, produção oral e produção escrita). Para realizar esta investigação nos baseamos nos pressupostos de Balboni (2010), dos quais falaremos mais adiante, além de nos fundamentarmos nos trabalhos realizados por Candido et al. (1977), Celani et al. (1988, 2009) e Mordente e Ferroni (2011a).

Ao final, apresentaremos as nossas primeiras conclusões e a importância da continuidade da pesquisa, que está sendo atualmente desenvolvida.

\section{História da língua italiana: o surgimento do italiano jurídico}

A partir da queda do Império Romano do Ocidente se aprofundaram, em toda a Europa, as diferenças entre o latim, empregado como língua culta pelos juristas e pelos eclesiásticos, e a língua falada pelo povo. Nasciam, assim, os idiomas "vulgares", precursores das línguas nacionais.

Na Itália, durante o Renascimento, houve inúmeras polêmicas literárias, que redundaram na dita questione della lingua (MIGLIORINI, 1967; MARAZZINI, 1999; ). Migliorini cita, na primeira metade do século, o surgimento de três correntes literárias, que foram largamente 
discutidas: a corrente arcaizante de Bembo, outra com inclinações para uma língua de tipo eclético e, enfim, a corrente toscana que indicava como modelo o florentino ou, mais genericamente, o toscano (MIGLIORINI, 1967). Ao final, a polêmica se resolveu a favor do modelo bembiano, que se tornou o cânone da literatura italiana.

O debate sobre a questione della lingua, considerado como o produto das reflexões nascidas da incerteza da norma linguística, atingiu o seu ápice nos séculos XVI e XIX e acompanhou cada um dos momentos de expansão do italiano, o seu crescimento e consequentemente as suas mudanças.

No que diz respeito ao processo de transformação linguística, o latim continuou, em vários campos, ocupando uma posição privilegiada durante muito tempo. Porém o uso do "vulgar" fez progressos na legislação e na linguagem jurídica (MIGLIORINI, 1967; DEVOTO, 1974; FIORELLI, 1994).

No entanto, no que tange ao surgimento do italiano jurídico, os primeiros textos reconhecidos como documentos escritos em vulgar foram os placiti cassinesi. Tratava-se de documentos jurídicos que diziam respeito a um litígio sobre a disputa de algumas terras. As partes do litígio eram o mosteiro beneditino de Montecassino e um agricultor local com o nome de Rodelgrimo d'Aquino. Nesses documentos, houve a transcrição de três testemunhos a favor dos monges, diante do juiz Arechisi. As testemunhas indicavam com um dedo o local da divisa que havia sido ocupada ilicitamente por um camponês, depois da destruição da abadia em 885 pelos sarracenos. Os documentos jurídicos são agrupados em quatro pergaminhos:

Os documentos em que, pela primeira vez, o vulgar aparece em plena luz, conscientemente contraposto ao latim, são os quatro "placiti cassinesi". Trata-se de um conjunto de quatro pergaminhos de argumento análogo (quatro plácidos ou, mais exatamente, três plácidos e um "memorando" sobre a posse de certas terras, nos quais a base para a decisão é fornecida por testemunhas juramentadas), pertencentes ao mesmo tempo (o breve período de 960 a 963) e aos mesmos lugares (MIGLIORINI, 1967, p. 91) ${ }^{1}$.

A oitiva das testemunhas foi colhida em volgare, sendo que esses textos forneceram a base para a fundamentação da decisão jurídica. A "fórmula" comunicada pelo juiz foi reproduzida e apresentada da seguinte maneira:

1 No original: "I documenti in cui per la prima volta il volgare appare in piena luce, coscientemente contrapposto al latino, sono i quatro placiti cassinesi. Si tratta di un gruppetto compatto di quatro pergamene di analogo argomento (quattro placiti o più esattamente tre placiti e un 'memoratorio' sull'appartenenza di certe terre, nei quali la base per la decisione è fornita da testimonianze giurate), appartenenti allo stesso tempo (il breve periodo dal 960 al 963 ) e agli stessi luoghi." 
(Capua, março de 960):

Sei que aquelas terras, naquelas fronteiras em que estão incluídas, trinta anos as possuíram os Beneditinos.

(Sessa, março de 963):

Sei que aquelas terras, naquelas fronteiras que lhe mostrei, e em que estão incluídas, pertenceram a Pergoaldo, que as possuiu durante trinta anos.

(Teano, julho de 963):

Aquelas terras, naquelas fronteiras que lhes mostrei, são de santa Maria, que trinta anos as possuiu.

(Teano, outubro 963):

Sei que aquelas terras, naquelas fronteiras que lhe mostrei, trinta anos as possuiu santa Maria. (MIGLIORINI, 1967, p. 92)².

Segundo Migliorini, esses documentos são os primeiros de uma linguagem cartorária, refletindo uma linguagem regional da Campania, habitualmente falada por juristas e eclesiásticos na segunda metade do século X: "mas aquela linguagem regional continha também elementos inter-regionais de duas espécies diferentes: latinismos e italianismos" (MIGLIORINI, 1967, p. 92).

Outro momento fundamental para a história da linguagem jurídica italiana foi, a partir do século XVIII, a chamada Era das Codificações, marcada principalmente pela elaboração do código de Napoleão e definida como a frequente elaboração de códigos, sobretudo nos estados europeus, sendo uns influenciados pelos outros. No tocante à Era das Codificações, Oliveira (2002), esclarece que se trata de um movimento jurídico aparecido no Ocidente no século XIX, em função do qual os direitos ocidentais, quanto à forma, se dividem em: direito continental, ou direito codificado, que compreende o grupo francês, tendo por ponto de partida o Código de Napoleão (Code Civil des Français) e o grupo alemão; e o sistema do Common Law ou do grupo Anglo-Americano.

Essa reforma de Napoleão foi importante para unificar e homologar a legislação e a terminologia jurídica italiana:

Sob o governo napoleônico instaurou-se um aparato administrativo e burocrático moderno e em 1806 no Reino itálico foi emanado o Código civil bilíngue, italiano

2 No original: “(Capua, marzo 960): Sao ko kelle terre, per kelle fini que ki contene, trenta anni le possette parte sancti Benedicti. (Sessa, marzo 963): Sao cco kelle terre, per kelle fini que tebe monstrai, Pergoaldi foro, que ki contene, et trenta anni le possette. (Teano, luglio 963): Kella terra, per kelle fini que bobe mostrai, sancte Marie è, et trenta anni la posset parte sancte Marie. (Teano, ottobre 963): Sao cco kelle terre, per kelle fini que tebe mostrai, trenta anni le possette parte sancte Marie." 
e francês, um passo importante para a difusão de uma terminologia jurídica unitária (ZOLLI, 1974). ${ }^{3}$

Em 1861, realizou-se a unificação da Itália, o que possibilitou a uniformização da língua que alcançaria todos os italianos. A escola, finalmente obrigatória para todos, contribuiu grandemente para a alfabetização de massa e para a difusão do italiano como língua nacional.

No texto da Constituição da República Italiana, promulgada em dezembro de 1947, e que entrou em vigor no dia 01 de janeiro de 1948, permanece evidente a preocupação a respeito da língua: "Todos os cidadãos possuem igual dignidade social e são iguais perante a lei, sem distinções de sexo, raça, de língua, de religião, de opiniões políticas, de condições pessoais e sociais." (Artigo 3) (grifo nosso). ${ }^{4}$

É necessário salientar que no século XIX a emigração, que foi acentuada nos anos de maior dificuldade econômica, torna-se estável e leva à formação de "pequenas Itálias" especialmente nos Estados Unidos, na Argentina e no Brasil, que recebeu uma parcela considerável de imigrantes italianos, os quais influenciaram fortemente a cultura brasileira, sendo que muitos descendentes mantiveram as tradições das famílias e conservaram a língua, passando de geração a geração.

Porém, no que tange ao italiano jurídico, o interesse principal advém do fato que o Direito Brasileiro sofreu influências do Direito Romano e até hoje são utilizados institutos jurídicos romanos:

A relevância do estudo do Direito Romano em países da Europa e da América Latina firmou-se em razão da influência do sistema romanista nos textos de suas codificações, as quais surgiram a partir do século XVIII. Portanto, para o jurista brasileiro, estudar o Direito Romano é conhecer as origens do Direito pátrio, sendo imprescindível o estudo do Direito Romano no início dos Cursos de Direito (SALERNO et al., 2006).

Do mesmo modo, podemos dizer que as experiências, as condições socioculturais, econômicas, jurídicas e científicas, contribuíram para a evolução linguística; mas, hoje, de acordo com Beccaria, estamos atravessando uma fase típica de todas as línguas modernas:

3 No original: "Sotto il governo napoleonico si instaurò un apparato amministrativo e burocratico moderno e nel 1806 nel Regno italico fu emanato il Codice civile in testo bilingue, italiano e francese, un passo importante per la diffusione di una terminologia giuridica unitaria."

4 No original: "Tutti i cittadini hanno pari dignità sociale e sono eguali davanti la legge, senza distinzione di sesso, razza, di lingua, di religione, di opinioni politiche, di condizioni personali e sociali” (art. 3) 
Agora, estamos atravessando outra fase, típica de todas as línguas modernas, devido à maior divisão do trabalho, que torna os falantes reciprocamente sempre mais distantes, incide sobre a própria compreensão dos discursos desenvolvidos pela mídia, pela escola, pelos centros de atividade política. O italiano setorizase, nascem léxicos particulares das várias técnicas ou atividades profissionais, estabilizam-se códigos corporativos, linguagens com circuito fechado (BECCARIA, 2002, p. 172). ${ }^{5}$

É neste contexto do uso da língua, com suas variedades funcionais, ou seja, com fins específicos, que se insere a pesquisa que apresentamos aqui, que teve com objetivo principal investigar como é tratado hodiernamente o ensino do italiano jurídico no Brasil.

\section{O ensino do italiano jurídico no Brasil}

Como já foi dito anteriormente, o direito italiano influenciou muito o brasileiro e, por esse motivo, os textos dos juristas italianos são frequentemente estudados pelos estudantes de direito e há um grande interesse por suas doutrinas. A nossa pesquisa surgiu da junção desses dois interesses: o interesse pelo Direito e o interesse pela língua italiana.

Durante nosso trabalho, pesquisamos acerca do ensino do italiano jurídico no Brasil. Em primeiro lugar, realizamos uma pesquisa no banco de teses da USP e de outras universidades para fazer um levantamento dos trabalhos realizados na área do italiano: encontramos trabalhos relacionados ao ensino de italiano com fins específicos, porém que pouco se referem ao ensino do italiano jurídico. Sabemos que há docentes que ensinam italiano para estudantes de Direito, que precisam fazer provas de proficiência do idioma ou seguir cursos na Itália, mas constatamos que não havia nenhum trabalho de pesquisa no que diz respeito ao ensino de italiano jurídico no Brasil. A partir desse primeiro levantamento, procuramos livros didáticos que propusessem o ensino de italiano para juristas e identificamos dois manuais produzidos na Itália: Una lingua in Pretura, il linguaggio del diritto (SEMPLICI, 1996) e Italiano per giuristi (FORAPANI, 2003).

A nossa primeira análise foi realizada com base nos conteúdos propostos por cada livro didático e na forma como estavam estruturadas as unidades didáticas. A partir dessa primeira observação, decidimos investigar como seria o aprendizado de um grupo de alunos com esses dois manuais. Propusemos então a realização de um curso para advogados na Casa do advogado

5 No original: Ora stiamo attraversando un'altra fase, tipica di tutte le lingue moderne, dovuta alla sempre più accentuata divisione del lavoro, che rende i parlanti reciprocamente sempre più estranei, incide a volte sulla stessa comprensibilità dei discorsi svolti dai mass media, dalla scuola, dai centri di attività politica. L'italiano si settorializza, nascono lessici privati delle varie tecniche o attività professionali, si stabilizzano dei codici corporativi, dei linguaggi a circuito chiuso. 
de Jundiaí e começamos o nosso trabalho de pesquisa com um grupo que estava dentro do perfil indicado nos dois manuais: alunos que tinham um conhecimento da língua italiana de nível intermediário e que atuavam na área do Direito.

Durante o percurso dessa pesquisa, apreendemos que para alunos que conhecem bem a linguagem técnica do Direito em português e tem um conhecimento básico do italiano, o livro Italiano per giuristi (FORAPANI, 2003) não apresentava dificuldades, enquanto que o livro Una Lingua in Pretura (SEMPLICI, 1996) era um pouco mais complexo, e demandava conhecimentos mais aprofundados da língua em relação às estruturas gramaticais e à compreensão do léxico específico. Essa primeira investigação nos levou a pensar que o primeiro manual poderia ser utilizado com alunos que fossem iniciantes absolutos do idioma italiano, o que nos encaminhou para a segunda fase da nossa pesquisa. Nesse segundo momento, decidimos realizar um curso de italiano para estudantes da Faculdade de Direito da Universidade de São Paulo, iniciantes absolutos no estudo do idioma.

Ao iniciarmos o curso, realizamos um questionário para levantar as necessidades e o perfil dos discentes. Seguem os dados coletados:

1. $60 \%$ dos estudantes eram graduandos e $40 \%$ dos estudantes eram pós-graduandos;

2. $55 \%$ eram iniciantes absolutos no idioma e $45 \%$ já haviam estudado a língua em algum momento;

3. $50 \%$ afirmaram ter interesse em adquirir conhecimento do italiano "comum" e do italiano jurídico; $25 \%$ desejavam aprender somente o italiano jurídico; $5 \%$ pretendiam estudar na Itália; $10 \%$ precisavam se preparar para fazer prova de proficiência; $5 \%$ desejavam conhecer o sistema jurídico italiano; $5 \%$ pretendiam se atualizar no italiano.

A análise desses dados nos levou a projetar um curso que englobava tanto o ensino da língua comum, quanto o ensino do italiano jurídico (BORELLO; BALDI 2004).

Esse curso propunha-se a desenvolver as quatro habilidades comunicativas: ler, ouvir (e entender o que se ouve), falar e escrever. As habilidades eram trabalhadas de forma integrada (BALBONI, 2010) e havia uma atenção especial para a aquisição do léxico jurídico (CORDA; MARELLO, 1999; MORTARA, 2001; BARNI et al., 2008).

Por não encontrar pesquisas realizadas no italiano com esse viés, procuramos nos basear nos cursos realizados na USP na década de 70, durante os quais o professor Antonio Candido realizou pesquisas com a língua com fins específicos na área do francês, trabalhando as 4 habilidades do 
idioma (CANDIDO et al., 1977). Pautamo-nos também nas experiências realizadas pela PUC-SP na área do inglês ${ }^{6}$ (CELANI et al., 2009).

A nossa pesquisa envolveu, portanto, a organização de cursos de italiano jurídico, com metodologia e materiais específicos, adequados para o desenvolvimento das quatro habilidades, cuja prática ajuda o aluno a se comunicar tanto no âmbito geral quanto no jurídico.

A metodologia adotada na pesquisa foi a seguinte:

1. Primeiramente, partindo das análises preliminares dos dois manuais para o ensino do italiano jurídico, identificamos (dentro do perfil do aluno indicado por tais livros) as dificuldades de produção oral e escrita dos discentes aos quais esses materiais são destinados. Propusemos uma avaliação em forma de apresentação de seminário e filmamos essa produção oral dos alunos. Essa apresentação foi realizada a partir de textos autênticos pesquisados por alunos (advogados) com o nível intermediário do idioma.

2. Em segundo lugar, desenvolvemos uma pesquisa de campo direcionada ao ensino do italiano jurídico para alunos principiantes no idioma. Para coletar os dados da nossa pesquisa, preparamos e ministramos um curso para um público específico. Esse curso foi elaborado para os alunos da Faculdade de Direito da Universidade de São Paulo, tendo o objetivo de desenvolver as quatro habilidades em língua italiana, agregando-as à competência da leitura de textos específicos da área jurídica.

Os cursos foram realizados ao longo de dois semestres, nos quais tivemos a oportunidade de avaliar as produções orais e escritas dos estudantes, observando, em tais produções, o uso de termos jurídicos e o uso da língua comum.

Ao final desse trabalho, analisamos os dados coletados, a partir da nossa experiência empírica, fazendo considerações sobre o primeiro curso ministrado aos alunos de nível intermediário, de acordo com o perfil indicado pelos manuais utilizados, e também sobre a viabilidade da estrutura do segundo curso proposto, o de italiano jurídico para iniciantes.

\section{Primeiras conclusões da pesquisa}

Em relação ao primeiro curso, no qual analisamos os dois manuais citados (Una lingua in Pretura e Italiano per giuristi), após as primeiras 40 horas de aula, decidimos, por

6 English for Specific Purposes (Inglês para fins específicos ou inglês instrumental). 
sugestão dos alunos, trabalhar também com o livro Elogio dei giudici scritto da un avvocato (CALAMANDREI, 2009) ${ }^{7}$. Este curso compreendeu um total de 80 horas de aula, durante as quais pudemos perceber claramente a evolução no que diz respeito à compreensão de textos escritos. Realizamos muitas atividades de comparação entre os institutos jurídicos dos dois países (Itália-Brasil), objetivando que os estudantes alcançassem uma melhor compreensão geral; e visando a permitir que, por conhecer o argumento tratado na própria língua, conseguissem absorver muito mais do conteúdo e com maior facilidade ao deparar-se com o mesmo tema na língua italiana. Entretanto, o desenvolvimento da oralidade não foi de acordo com o esperado, porque acreditávamos que esses alunos conseguiriam chegar a um nível avançado na produção oral, mas entendemos que o tempo de curso teria que ser maior para conseguirmos atingir com satisfação esse objetivo.

Para os cursos realizados com estudantes que eram iniciantes no estudo do idioma, pudemos perceber que ao final dos dois módulos do curso (total de 84 horas de aula): conseguiam entender e usar expressões simples do cotidiano; eram capazes de apresentar-se e apresentar outras pessoas formulando perguntas e respostas pessoais; interagiam de modo simples, desde que a outra pessoa falasse com clareza; compreendiam frases e expressões usadas no âmbito jurídico; compreendiam, com facilidade, textos jurídicos (não muito complexos); expressavam, de modo simples, ideias e opiniões relacionadas ao Direito; eram capazes de produzir textos simples relacionados ao interesse pessoal e jurídico.

Podemos dizer que foi possível trabalhar as quatro habilidades em nível elementar e, o mais importante, conseguiam compreender facilmente textos de grau médio de dificuldade, pois, já haviam aprendido a utilizar estratégias de leitura, que podem ser aplicadas a qualquer gênero textual.

No entanto, a coleta de dados nos permitiu visualizar uma lacuna no ensino do italiano jurídico no Brasil, pois não há trabalhos de pesquisas formais realizados, nem tampouco materiais próprios para estudantes lusófonos.

Levando em consideração a ausência de materiais para estudantes brasileiros de italiano jurídico, acreditamos que a elaboração de material didático para ensinar o italiano com fins específicos para estudantes brasileiros de Direito deva levar em consideração as particularidades de quem fala a língua portuguesa. Para os falantes do português, língua de origem latina, tanto quanto o italiano, as dificuldades são diferentes das de outros estudantes, que falam outras línguas. Acreditamos que, ao utilizarmos as similaridades dos dois idiomas, os alunos podem aprender com mais facilidade, partindo do conhecimento pré-construído, tanto pelo que diz respeito à língua, quanto ao próprio direito.

7 O livro foi escrito pelo jurista italiano, Piero Calamandrei, sendo que a primeira edição foi escrita entre 1935 e 1956 e conta com uma tradução para o português com o título "Eles, os Juízes, vistos por um advogado" editada pela Martins Fontes (2000). A leitura deste livro é indicada nas faculdades de Direito, nos primeiros anos de estudo. 


\section{Considerações finais}

Não foi o nosso objetivo, neste estudo, criticar métodos ou abordagens, mas analisar, segundo os critérios dos autores que selecionamos como referência e mencionamos na introdução, durante o desenvolvimento de um curso, o que funciona com determinado grupo de alunos lusófonos, eliminando aquilo que percebemos que não foi bem aceito por eles. Com base em Kumaravadivelu (2003), que preconiza que a condição pós-método permite que o professor construa teorias a partir da própria prática, criando específicas estratégias de ensino, acreditamos que para o sucesso de um aprendizado não basta ter um livro didático, mas é necessário ter autonomia para lecionar, o que ajuda no desenvolvimento da autocrítica, permitindo a avaliação do nosso modo de ensinar, construindo e reconstruindo novas formas de trabalhar com os alunos durante as aulas.

Além disso, temos plena consciência de que, apesar da divisão clássica entre a escrita e a fala, as duas modalidades misturam-se e é difícil traçar uma linha de separação entre elas (MONDAVIO, 2013). Por esse motivo, não trabalhamos separadamente as habilidades, mas de maneira totalmente integrada (BALBONI, 2010).

No que diz respeito às habilidades integradas, consideramos de suma importância o papel do léxico de especialidade como fator na construção de sentidos. A chamada Abordagem Lexical, primeiramente proposta por Lewis (1993), “[...] não se opõe aos princípios da Abordagem Comunicativa, mas coloca o léxico em igualdade de importância com a gramática", conforme explicado por Zucchi (2010).

Dando continuidade a todo o trabalho realizado, o que pretendemos desenvolver é a elaboração de materiais didáticos específicos para o público de estudantes brasileiros de Direito que têm interesse em aprender o italiano jurídico.

\section{Referências}

BALBONI, P. E., Imparare le lingue straniere. Venezia: Marsilio Editori, 2010.

BARNI, M., TRONCARELLI, D., BAGNA, C., Lessico e apprendimenti: il ruolo del lessico nella linguistica educativa. Milano: FrancoAngeli, 2008.

BECCARIA, G. L., Italiano: antico e nuovo. Perugia: Garzanti, 2002.

BORELLO, E.; BALDI B., Settore che vai, linguaggio che trovi. Genova: Il Libraccio, 2004 
CALAMANDREI, P., Eles, os Juizes, vistos por um advogado. São Paulo: Editora Martins Fontes, 2000.

, Elogio dei giudici, scritto da un avvocato. Milano: Ponte alle Grazie, 1999 [1935].

CANDIDO, A., CARONI, I., LAUNAY, M., O Francês Instrumental: A experiência da Universidade de São Paulo. São Paulo: HEMUS-Livraria editora Ltda., 1977.

CELANI, M.A.A., FREIRE, M.M., RAMOS, R.C.G., A abordagem instrumental no Brasil: um projeto, seus percursos e seus desdobramentos. Campinas-SP: Mercado das Letras, 2009.

CORDA, A.; MARELLO, C. Lessico Insegnarlo e impararlo. Torino: Paravia, 1999.

DEVOTO, G. Il linguaggio d'Italia: storia e strutture linguistiche italiane dalla preistoria ai nostri giorni. Milano: Rizzoli, 1974.

FIORELLI, P. La lingua del diritto e dell'amministrazione. In: SERIANNI, L., TRIFONE, P. (a cura di), Storia della lingua italiana. $2^{\circ}$ v. Torino: Einaudi, 1994.

FORAPANI, D., Italiano per giuristi. Firenze: Alma Edizioni, 2003.

ITÁLIA. La Costituzione della Repubblica Italiana. Disponível em:

http://governo.it/Governo/Costituzione/principi.html. Acesso em janeiro 2011.

KUMARAVADIVELU, B. Understanding language teaching: from Method to Postmethod. New Jersey: LEA, 2006.

LEWIS, M. The Lexical Approach: the state of ELT and a way forward. Hove: LTP, 1993.

MASTELARO, Q.R.A. Análise de materiais e propostas de cursos para o ensino do italiano jurídico. 2013. 248 f. Dissertação (Mestrado), Faculdade de Filosofia, Letras e Ciências Humanas da Universidade de São Paulo, São Paulo, 2014.

MARAZZINI, C. Da Dante alla lingua selvaggia: sette secoli di dibattito sull'italiano. Roma: Carocci, 1999.

MIGLIORINI, B. Storia della lingua italiana. Milano: Bompiani, 1967.

MONDAVIO, A. Abilità relative alla lettura e alla scrittura. Ministero degli Affari Esteri. Disponível em http://www.italicon.it/it/modulo.asp?M=M00363. Acesso em janeiro de 2013.

MORDENTE, O.; FERRONI, R. O ensino do italiano instrumental. São Paulo: Humanitas, 2011a. , Habilidade de leitura em italiano no contexto universitário. São Paulo: Humanitas, 2011b.

MORTARA, G. B., Le parole e la giustizia. Divagazioni grammaticali e retoriche su testi giuridici italiani. Torino: Einaudi, 2001.

OLIVEIRA, A. S., A codificação do Direito. Revista Jus Navigandi, ano 7, n. 60, 1 nov. 2002. Disponível em: <https://jus.com.br/artigos/3549>. Acesso em: 13 maio 2016. 
SALERNO, M. et al. A importância do Direito Romano na formação do jurista brasileiro. Semina: Ciências Sociais e Humanas, Londrina, v. 27, n.2, p. 125-133, jul./dez. 2006. Disponível em: http://www. uel.br/revistas/uel/index.php/seminasoc/article/view/3744/3005. Acesso em 10 de maio de 2016.

SEMPLICI, S., Una lingua in Pretura, il linguaggio del diritto. Roma: Bonacci, 1996.

ZOLLI, P., Saggi sulla lingua italiana dell'Ottocento, Pisa: Ed. Pacini, 1974.

ZUCCHI, A. M. T., O dicionário no estudo de línguas estrangeiras: os efeitos de seu uso na compreensão escrita em italiano. Tese de Doutorado. Faculdade de Filosofia, Letras e Ciências Humanas da Universidade de São Paulo. São Paulo, 2010.

Recebido em 25/05/2016

Aprovado em 18/10/2016 